\title{
Seletividade do Herbicida Tembotrione à Cultura do Milheto ${ }^{1}$
}

\author{
Selectivity of the Herbicide Tembotrione to Pearl Millet
}

\author{
DAN, H.A. ${ }^{2}$, BARROSO, A.L.L. ${ }^{3}$, DAN, L.G.M. ${ }^{4}$, OLIVEIRA JR., R.S. ${ }^{5}$, PROCÓPIO, S.O. ${ }^{6}$, \\ FREITAS, A.C.R. ${ }^{7}$ e CORREA, F.M. ${ }^{8}$
}

\begin{abstract}
RESUMO - O presente trabalho teve por objetivo avaliar a seletividade do herbicida tembotrione aplicado em pós-emergência na cultura do milheto. Foram realizados dois ensaios, avaliandose primeiramente o efeito do herbicida sobre três cultivares de milheto (ADR-300, ADR-500 e ADR-7010) em casa de vegetação. Posteriormente, o híbrido ADR-7010 foi submetido, no campo, a doses crescentes de tembotrione aplicadas em dois estádios de desenvolvimento das plantas (quatro e sete folhas completamente desenvolvidas). Em casa de vegetação, os cultivares apresentaram percentuais semelhantes de redução no acúmulo de matéria seca da parte aérea, após utilização de $75,5 \mathrm{~g} \mathrm{ha}^{-1}$ no estádio de quatro folhas expandidas. Em campo, o tembotrione mostrou maior potencial de intoxicação ao ser aplicado nos estádios mais precoces do híbrido ADR-7010. A seletividade do tembotrione é alterada em função da dose e do estádio fenológico da cultura do milheto no momento da aplicação do herbicida. O uso de tembotrione na cultura do milheto em áreas destinadas à produção de grãos mostrase uma alternativa viável no controle de plantas daninhas.
\end{abstract}

Palavras-chave: plantas daninhas, Pennisetum glaucum, tricetonas

\begin{abstract}
The present study was carried out to evaluate the selectivity of the herbicide tembotrione, applied at post-emergence of pearl millet. Two experiments were conducted, evaluating primarily the effect of the herbicide on three pearl millet cultivars (ADR-300, ADR-500 and ADR-7010) under greenhouse conditions. The hybrid ADR-7010 was latertested under field conditions, when increasing doses of tembotrione were applied at two stages of plant development (fou and seven fully developed leaves). Under greenhouse conditions, the cultivars presented similar percentages of reduction of shoot dry matter accumulation, aftertembotrione application at $75.5 \mathrm{~g} \mathrm{ha}^{-1}$ at the four-expanded leaf stage. Under field conditions, tembotrione showed the highest phytotoxicity when applied at the early stages of hybrid ADR-7010. Tembotrione selectivity is dependent on the dose and developmental stage of pearl millet at the time of herbicide application. The use of tembotrione over growing millet in areas intended for grain production was found to be a viable alternative to weed control.
\end{abstract}

Keywords: weeds, Pennisetum glaucum, tricetones.

\section{INTRODUÇÃO}

O milheto (Pennisetum glaucum) é uma espécie originária do continente africano com dupla aptidão, servindo tanto para a produção de forragem destinada à produção animal quanto para consumo humano (grãos) (Scaléa, 1998). É uma gramínea muito utilizada nas regiões de clima tropical, de ciclo anual, hábito de crescimento ereto, porte alto, com

1 Recebido para publicação em 7.12.2009 e na forma revisada em 12.11.2010.

2 Doutorando do Programa de Pós-Graduação em Agronomia, Universidade Estadual de Maringá - UEM/NAPD, Av. Colombo 5790, 87020-900 Maringá-PR, < halmeidadan@gmail.com>; ${ }^{3}$ Professor da Faculdade de Agronomia, FESURV; ${ }^{4}$ Mestranda, Programa de Pós-Graduação em Agronomia, UEM; ${ }^{5}$ Professor do Dep. de Agronomia, Universidade Estadual de Maringá, UEM/NAPD; ${ }^{6}$ Pesquisador, Embrapa Tabuleiros Costeiros, 49025-040 Aracaju-SE; ${ }^{7}$ Graduando(a) em Agronomia, FESURV; ${ }^{8}$ Doutorando, Programa de Pós-Graduação em Estatística Experimental, Universidade Federal de Lavras - UFLA. 
desenvolvimento uniforme e bom perfilhamento, mesmo em condições de baixa disponibilidade hídrica (Kissmann, 2007).

Devido à sua grande adaptação e difusão no bioma dos cerrados, vem ganhando destaque nos últimos anos, especialmente após o lançamento de híbridos de alto potencial produtivo, oriundos do melhoramento genético. Isso fez com que essa planta deixasse de ser uma simples espécie de cobertura ou produção de palha para o plantio direto, passando a ser considerada uma cultura de valor econômico para produção de grãos e forragem.

Apesar da rusticidade, o milheto apresenta crescimento inicial lento, tornando-se vulnerável à interferência causada pela matocompetição. Nesse contexto, as plantas daninhas podem se tornar um fator limitante para o desenvolvimento da cultura. Segundo Carson (1987), a ausência de controle das plantas daninhas durante o período crítico de prevenção da interferência, que vai de duas até sete semanas após a emergência das plantas, pode reduzir a produtividade de grãos em até $36 \%$. Para Berglund (1998), o controle de plantas daninhas nessa cultura deve ser realizado precocemente, pois as plantas de milheto só toleram a presença de plantas daninhas até atingirem de 15 a $20 \mathrm{~cm}$ de altura.

Assim como na maioria das espécies cultivadas, o controle químico é uma ferramenta imprescindível no manejo integrado de plantas daninhas, principalmente em cultivos extensivos. Apesar de ser uma espécie que vem ganhando destaque na região dos cerrados, não existe no mercado brasileiro nenhum herbicida registrado para uso na cultura do milheto (Pereira Filho et al., 2003). Controle flexivel e eficiente de espécies latifoliadas tem sido obtido com atrazine (Ndahi et al., 1980), 2,4-D (Farinelli et al., 2005; Pacheco et al., 2007) e carfentrazone-ethyl (Lyon et al., 2007); contudo, opções para o controle de gramíneas na cultura do milheto ainda não foram identificadas.

Dentre os herbicidas de ação graminicida e latifolicida com potencial para utilização em pós-emergência na cultura do milheto, destacam-se os inibidores de carotenoides, sobretudo os que inibem a enzima hydroxyphenylpyruvate dioxygenase (HPPD) (Dan et al., 2009). Esses herbicidas promovem branqueamento nas folhas, resultado da degradação oxidativa da clorofila e da membrana plasmática, gerando extravasamento do conteúdo celular e causando a necrose dos tecidos (Mitchell et al. 2001; Grossmann \& Ehrhardt, 2007).

Algumas espécies cultivadas, como o mi1ho, apresentam tolerância a esses herbicidas. Nesse caso, a seletividade dos herbicidas inibidores da HPPD ocorre pelo rápido metabolismo de suas moléculas, devido principalmente à ação da hemoproteína citocromo P-450 (Mitchell et al., 2001; Pataky et al., 2008).

O herbicida tembotrione - lançado recentemente no Brasil para uso em pós-emergência na cultura do milho - tem apresentado desempenho satisfatório no controle de plantas daninhas, sobretudo de gramineas. Ao avaliar os herbicidas mesotrione, topramesone e tembotrione no controle de plantas daninhas na cultura do milho, Bollman et al. (2008) constataram que o tembotrione causou menor injúria quando comparado aos demais.

Para que a cultura do milheto continue se expandindo no nosso país, é de fundamental importância a identificação de herbicidas de aplicação em pós-emergência, com ação sobre gramineas que apresentem seletividade a essa cultura. Nesse contexto, o objetivo do presente trabalho foi avaliar a seletividade do herbicida tembotrione à cultura do milheto, em aplicações realizadas em dois estádios fenológicos.

\section{MATERIAL E MÉTODOS}

Dois experimentos foram conduzidos durante o período de dezembro de 2008 a abril de 2009, no município de Rio Verde-GO (17047’24" S, 5056’31" W e 698 de altitude). Ambos os experimentos foram implantados em Latossolo Vermelho distroférrico, apresentando as seguintes características: $\mathrm{pH}$ em água: 6,1 ; Ca: $2,36 \mathrm{cmol}_{\mathrm{c}} \mathrm{dm}^{-3} ; \mathrm{Mg}: 1,1 \mathrm{cmol}_{\mathrm{c}} \mathrm{dm}^{-3} ; \mathrm{Al}$ : $0,01 \mathrm{cmol}_{\mathrm{c}} \mathrm{dm}^{-3} ; \mathrm{K}: 35 \mathrm{mg} \mathrm{dm}^{-3}$; P: 2,07 $\mathrm{mg} \mathrm{dm}^{-3}$; CTC: 9,6 $\mathrm{cmol}_{\mathrm{c}} \mathrm{dm}^{-3}$; MO: 21,67 $\mathrm{g} \mathrm{kg}^{-1}$; argila: $280 \mathrm{~g} \mathrm{~kg}^{-1}$; silte: $400 \mathrm{~g} \mathrm{~kg}^{-1}$; e areia: $320 \mathrm{~g} \mathrm{~kg}^{-1}$.

\section{Experimento em casa de vegetação}

As unidades experimentais foram compostas de vasos com $10 \mathrm{dm}^{3}$ de solo. No momento 
da semeadura, realizou-se adubação de base equivalente a $60 \mathrm{~kg} \mathrm{ha}^{-1}$ de $\mathrm{P}_{2} \mathrm{O}_{5}$ (superfosfato simples), $20 \mathrm{~kg} \mathrm{ha}^{-1}$ de $\mathrm{K}_{2} \mathrm{O}$ (cloreto de potássio) e $20 \mathrm{~kg} \mathrm{ha}^{-1}$ de nitrogênio (sulfato de amônia).

O ensaio foi conduzido em delineamento inteiramente casualizado com seis repetições, em esquema fatorial $3 \times 2$, correspondendo a três cultivares de milheto (ADR-300, ADR-500 e ADR-7010), submetidos a duas doses de tembotrione (Soberan ${ }^{\circledR}$ ): 0 e 75,5 g i.a. ha ${ }^{-1}$.

A semeadura foi realizada a $1,5 \mathrm{~cm}$ de profundidade; uma semana após a emergência, as plântulas foram desbastadas, sendo mantidas três plantas por unidade experimental. A irrigação foi realizada mantendo-se $70 \%$ da capacidade de campo.

Os tratamentos foram aplicados no estádio fenológico de cinco folhas completamente expandidas, cerca de 22 dias após a emergência da cultura. A aplicação foi realizada com pulverizador costal com pressurização por $\mathrm{CO}_{2}$, munido de quatro pontas de pulverização do tipo TT 110-02 (barra de $2 \mathrm{~m}$ e 0,5 m entre pontas), utilizando volume de calda equivalente a $100 \mathrm{~L} \mathrm{ha}^{-1}$. Foi adicionado à calda $0,5 \% \mathrm{v} / \mathrm{v}$ de óleo vegetal (Áureo ${ }^{\circledR}$ ). As condições ambientais no momento das aplicações eram: temperatura, $25,1^{\circ} \mathrm{C}$; umidade relativa do ar (UR), $81 \%$; e velocidade média do vento, $2,1 \mathrm{~km} \mathrm{~h}^{-1}$.

As avaliações de intoxicação foram realizadas aos 7, 14 e 21 dias após a aplicação dos tratamentos (DAA), utilizando-se escala percentual de 0 a $100 \%$, em que $0 \%$ representa ausência de sintomas e $100 \%$, morte de todas as plantas. Determinou-se ainda, aos 43 dias após a emergência, a matéria seca de toda a parte aérea das plantas, a qual, após coleta, foi seca em estufa com circulação de ar a $65^{\circ} \mathrm{C}$ durante 72 horas.

Os resultados referentes à matéria seca foram submetidos à transformação $(\sqrt{ } \mathrm{x}+1)$ para seguir os pressupostos necessários à análise de variância, que foi realizada com o programa estatístico Sisvar. As médias das variáveis significativas foram comparadas pelo teste de Tukey a $5 \%$ de probabilidade.

\section{Experimento em campo}

A semeadura do milheto (cv. ADR-7010) ocorreu na terceira semana de janeiro de
2009. As unidades experimentais constaram de parcelas de $21 \mathrm{~m}^{2}$, onde o milheto foi semeado na densidade de seis sementes por metro, com espaçamento de 0,5 m entre linhas. Antes da semeadura, que ocorreu logo após a colheita da soja, a área foi dessecada com 1.080 g e.a. ha- ${ }^{-1}$ de glyphosate. No momento da semeadura, realizou-se uma adubação de base, composta de $150 \mathrm{~kg}$ de N-P-K, 8-20-18. Foram realizadas ainda duas adubações de cobertura de $20 \mathrm{~kg} \mathrm{ha}^{-1}$ de nitrogênio (sulfato de amônia), aos 14 e 33 dias após a emergência da cultura.

O ensaio foi conduzido no delineamento de blocos casualizados com quatro repetições, em esquema fatorial $5 \times 2$, correspondendo a cinco doses de tembotrione $\left(\operatorname{Soberan}^{\circledR}\right): 0,63$, 126, 189 e 252 g i.a. ha ${ }^{-1}$, aplicadas em dois estádios fenológicos da cultura: estádio 1 (plântulas com quatro folhas completamente expandidas, 18 dias após a emergência da cultura) e estádio 2 (plantas com sete folhas e dois afilhos, 26 dias após a emergência).

A aplicação dos tratamentos herbicidas foi feita com o mesmo equipamento e volume de calda descrito no experimento de casa de vegetação. Foi adicionado à calda $0,5 \%$ v/v de óleo vegetal (Áureo $\left.{ }^{\circledR}\right)$. As condições ambientais no momento das aplicações foram as seguintes: estádio 1 - temperatura média de $25,1{ }^{\circ} \mathrm{C}$, UR média de $81 \%$ e velocidade do vento média de $2,1 \mathrm{~km} \mathrm{~h}^{-1}$; e estádio 2 - temperatura média de $26,2{ }^{\circ} \mathrm{C}$, UR média de $82 \%$ e velocidade do vento média de $2,4 \mathrm{~km} \mathrm{~h}^{-1}$ ).

As avaliações de intoxicação foram realizadas aos 7, 14 e 21 dias após a aplicação dos tratamentos (DAA), utilizando-se escala percentual descrita no experimento de casa de vegetação. Aos $45 \mathrm{DAE}$ foi realizada avaliação da população, por meio da contagem do número de plantas emergidas em $2 \mathrm{~m}$ lineares, localizados nas linhas centrais da parcela. Determinou-se ainda a altura das plantas (do colo da planta à extremidade final da espiga) aos 55 dias após a emergência; a matéria seca da parte aérea foi obtida no início do florescimento da cultura, por meio da coleta de $1 \mathrm{~m}$ linear. Ao final da fase reprodutiva determinou-se o rendimento de grãos, estimado por meio da colheita de $2 \mathrm{~m}$ lineares de área útil da parcela, sendo a umidade corrigida para $13 \%$.

Planta Daninha, Viçosa-MG, v. 28, n. 4, p. 793-799, 2010 
Os resultados referentes aos niveis de intoxicação foram submetidos à transformação $(\sqrt{ } \mathrm{x}+1)$ para seguir os pressupostos necessários à análise de variância, que foi realizada com o programa estatístico Sisvar. Foram ajustados modelos de regressão para as variáveis-resposta, utilizando-se posteriormente o programa Sigma Plot para confecção das curvas de regressão.

\section{RESULTADOS E DISCUSSÃO}

\section{Experimento em casa de vegetação}

Aos sete dias após a aplicação do herbicida (DAA) (Tabela 1), observou-se branqueamento de folhas, típico dos herbicidas inibidores da sintese de pigmentos carotenoides, semelhantes aos observados por Felix \& Doohan (2005) e Dan et al. (2009). Durante esse período, todos os cultivares apresentaram intoxicação em relação às plantas que não receberam o herbicida, sendo a intensidade dos sintomas variável entre 17 e $23 \%$. Nessa avaliação, o cultivar ADR-7010 apresentou maior nível de injúrias em relação ao cultivar ADR-300. Embora tenha havido injúrias perceptiveis em todos os cultivares aos 7 DAA, todos apresentaram recuperação dos efeitos iniciais do herbicida, constatando-se injúrias inferiores a $10 \%$ aos 14 DAA (Tabela 1), e nenhum sintoma visual foi perceptivel aos 21 DAA (Tabela 1).

Quanto ao acúmulo de biomassa seca da parte aérea, avaliado aos 43 dias após a aplicação do tembotrione (Tabela 1), verificaramse efeitos negativos da aplicação do herbicida em todos os cultivares de milheto. Observouse também que os cultivares não diferiram quanto ao grau de sensibilidade ao herbicida, após a utilização de $75,5 \mathrm{~g}^{\text {ha }}{ }^{-1}$ de tembotrione na cultura do milheto.

Diante desses resultados, constatou-se a importância de avaliar a relação dose-resposta em diferentes estádios de aplicação. Além disso, passou a ser relevante avaliar se a cultura do milheto seria, em condições de campo, capaz de recuperar-se em termos de crescimento e produtividade em relação às injúrias observadas logo após a aplicação do tembotrione. Uma vez que não foram observadas diferenças significativas entre os cultivares quanto à matéria seca acumulada, optou-se por avaliar o híbrido ADR-7010 para o ensaio de campo, em razão da maior aptidão deste para a produção de grãos na região dos cerrados.

\section{Experimento em campo}

Os resultados da análise de variância (Tabela 2) indicaram que houve interação significativa $(P \leq 0,05)$ entre os tratamentos (doses e épocas de aplicação) para as variáveis intoxicação (7 e 21 DAA), matéria seca, altura de planta e produtividade do milheto.

O cultivar de milheto ADR-7010 apresentou diferentes niveis de intoxicação quando submetido a doses crescentes de tembotrione. Dentro do intervalo de doses estudado, observou-se que os níveis de intoxicação máximos apresentados aos 7 DAA foram de 63 e 54\%, para aplicações realizadas no momento em que as plantas se encontravam com quatro e

Tabela 1 - Intoxicação e matéria seca da parte aérea (MSPA), obtidas em função da dose do herbicida tembotrione e do cultivar de milheto

\begin{tabular}{|l|c|c|c|c|c|}
\hline \multirow{2}{*}{ Cultivar } & \multicolumn{3}{|c|}{ Intoxicação (\%) } & \multicolumn{2}{c|}{ MSPA (g) } \\
\cline { 2 - 6 } & 7 DAA & 14 DAA & 21 DAA & 0,0 & 75,5 \\
\hline ADR-300 & 17,5 & 8,3 & 1,0 & $6,32 \mathrm{aB}$ & $5,95 \mathrm{aA}$ \\
\hline ADR-500 & 19,3 & 10,2 & 1,6 & $5,64 \mathrm{aB}$ & $5,17 \mathrm{aA}$ \\
\hline ADR-7010 & 23,5 & 9,3 & 2,1 & $5,98 \mathrm{aB}$ & $5,55 \mathrm{aA}$ \\
\hline CV (\%) & \multicolumn{3}{|c}{} & & \multicolumn{2}{c|}{13,21} \\
\hline
\end{tabular}

Médias seguidas de mesma letra, minúscula na coluna e maiúscula na linha, não diferem entre si pelo teste de Tukey $p \geq 0,05$.

Tabela 2 - Rendimento de grãos da cultura do milheto, em função da dose do herbicida tembotrione e do estádio das plantas no momento da aplicação

\begin{tabular}{|c|c|c|}
\hline \multirow{2}{*}{$\begin{array}{c}\text { Dose de tembotrione } \\
\left(\mathrm{g} \mathrm{ha}^{-1}\right)\end{array}$} & \multicolumn{2}{|c|}{ Produtividade $\left(\mathrm{kg} \mathrm{ha}^{-1}\right)$} \\
\cline { 2 - 3 } & $\begin{array}{c}4 \text { folhas } \\
\text { expandidas }\end{array}$ & $\begin{array}{c}7 \text { folhas } \\
\text { expandidas }\end{array}$ \\
\hline 0 & $2.775 \mathrm{aA}$ & $2.691 \mathrm{aA}$ \\
\hline 63 & $2.690 \mathrm{aA}$ & $2.732 \mathrm{aA}$ \\
\hline 126 & $2.499 \mathrm{bA}$ & $2.535 \mathrm{aA}$ \\
\hline 189 & $1.983 \mathrm{cA}$ & $2.265 \mathrm{bB}$ \\
\hline 252 & $1.690 \mathrm{dA}$ & $2.095 \mathrm{bB}$ \\
\hline $\mathrm{CV}(\%)$ & \multicolumn{2}{|c}{12,3} \\
\hline
\end{tabular}

Médias seguidas de mesma letra, minúscula na coluna e maiúscula na linha, não diferem entre si pelo teste de Tukey $\mathrm{p} \geq 0,05$. 
sete folhas completamente expandidas, respectivamente (Figura 1A). Contudo, analisando as equações lineares ajustadas (Figura 1), observa-se que, para o intervalo de 75 a $100 \mathrm{~g} \mathrm{ha}^{-1}$ (doses recomendadas para tembotrione em milho), os valores de intoxicação variaram entre 18 e $24 \%$ para o estádio de quatro folhas e entre 13 e $18 \%$ quando aplicado no estádio de sete folhas.

Os demais sintomas pronunciados de intoxicação no campo (7 DAA) foram semelhantes aos observados em casa de vegetação (branqueamento das folhas e manchas de coloração rosada ou violácea, principalmente nas folhas novas). Resultados semelhantes foram observados por Karam et al. (2003), com utilização de clomazone na cultura do milho,
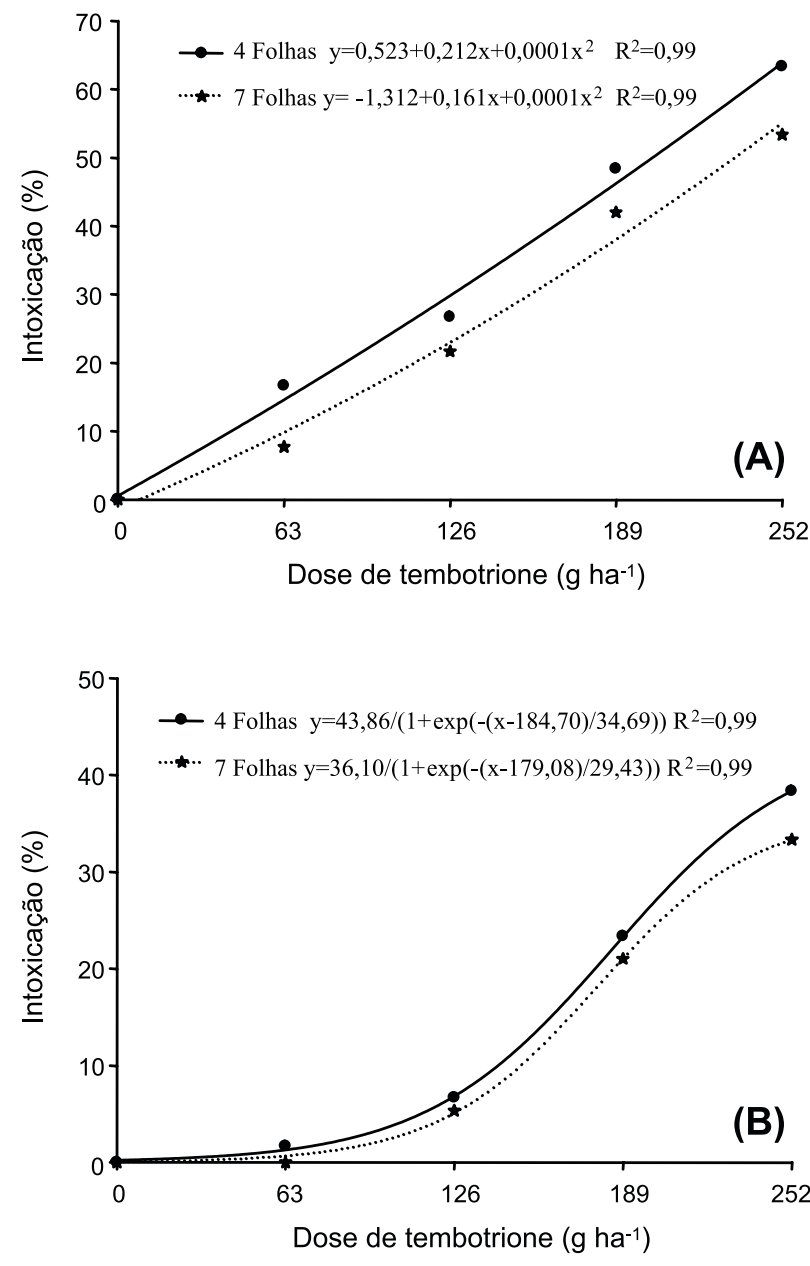

Figura 1 - Intoxicação em plantas de milheto aos 7(A) e 21(B) dias após a aplicação do herbicida tembotrione, em função da dose e do estádio das plantas no momento da aplicação. e por Felix \& Doohan (2005), em plantas de sorgo submetidas ao mesotrione. Segundo Grossmann \& Ehrhardt (2007), a inibição da síntese de carotenoides causada pela ação do herbicida leva à decomposição da clorofila pela luz, como resultado da perda da fotoproteção fornecida pelos carotenoides. Esse fato resulta na degradação oxidativa da clorofila e, em casos mais extremos, na oxidação das membranas celulares.

Aos 21 DAA, as plantas tratadas com doses de até $126 \mathrm{~g} \mathrm{ha}^{-1}$ de tembotrione se recuperaram e demonstraram intoxicação menor que 10\% (Figura 1B). De acordo com Mitchell et al. (2001), a seletividade e a grande capacidade de recuperação dos sintomas causados pelos herbicidas pertencentes à família das tricetonas ocorrem em razão do rápido metabolismo do HPPD, por meio do processo da hidroxilação. Pataky et al. (2008) observaram que a hemoproteína citocromo P-450 é a responsável por esse processo de detoxificação.

Um dos reflexos da utilização de doses a partir de $189 \mathrm{~g} \mathrm{ha}^{-1}$ de tembotrione foi a redução da população e do número de afilhos produzidos por planta. Esse fato ocorreu com maior frequência na aplicação precoce (quatro folhas expandidas). A aplicação mais tardia apresentou pouco reflexo sobre essas duas variáveis fato possivelmente relacionado à maior tolerância da espécie em função do estádio mais avançado de desenvolvimento.

Acréscimos na dose de tembotrione diminuíram o acúmulo de matéria seca da parte aérea do milheto (Figura 2). Caso se considere aceitável uma redução de até $10 \%$ na matéria seca, as doses máximas (calculadas pelas equações ajustadas aos dados) para utilização no milheto seriam de 116 e $118 \mathrm{~g} \mathrm{ha}^{-1} \mathrm{de}$ tembotrione, para aplicações no estádio de quatro e sete folhas, respectivamente. Entretanto, a utilização de $75 \mathrm{~g} \mathrm{ha}^{-1}$ proporcionou reduções variando de 2 a $3 \%$ para aplicações no estádio de quatro e sete folhas, respectivamente. Avaliando os niveis de sensibilidade de 85 híbridos de sorgo ao herbicida mesotrione, Abit et al. (2009) constataram que $80 \%$ dos cultivares avaliados apresentaram reduções significativas no acúmulo de massa seca após a exposição a $91 \mathrm{~g} \mathrm{ha}^{-1}$ de mesotrione. 
A altura das plantas seguiu a mesma tendência das demais já apresentadas; a utilização de tembotrione apresentou maior potencial supressor em aplicação mais precoce no milheto (Figura 3). A redução na altura das plantas foi diretamente proporcional à dose utilizada na aplicação, embora esse decréscimo tenha se mantido em valores inferiores a $10 \%$, não sendo, portanto, suficiente para prejudicar a operação de colheita mecanizada dos grãos.

A produção de grãos das plantas de milheto foi influenciada pela dose e época de aplicação

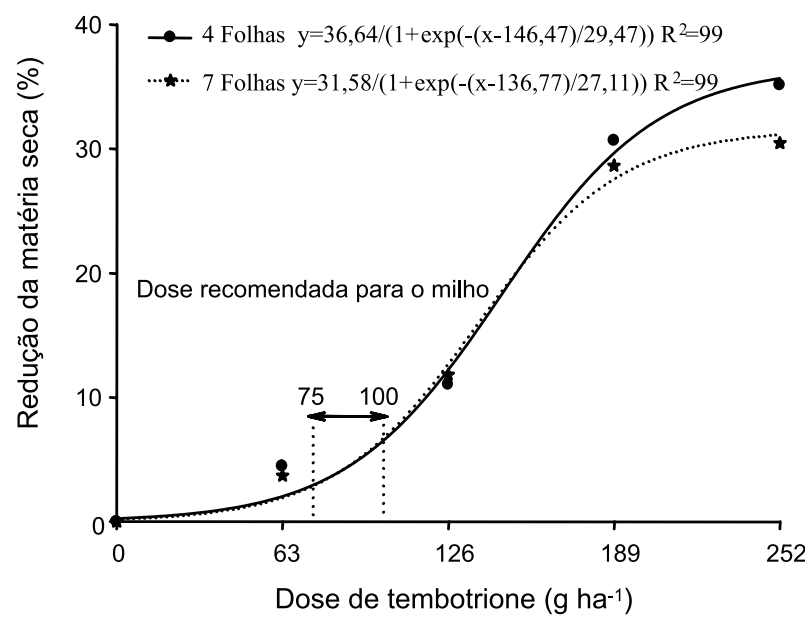

Figura 2 - Redução da matéria seca da parte aérea de plantas de milheto, aos 55 dias após a aplicação do herbicida tembotrione, em função da dose e do estádio das plantas no momento da aplicação.

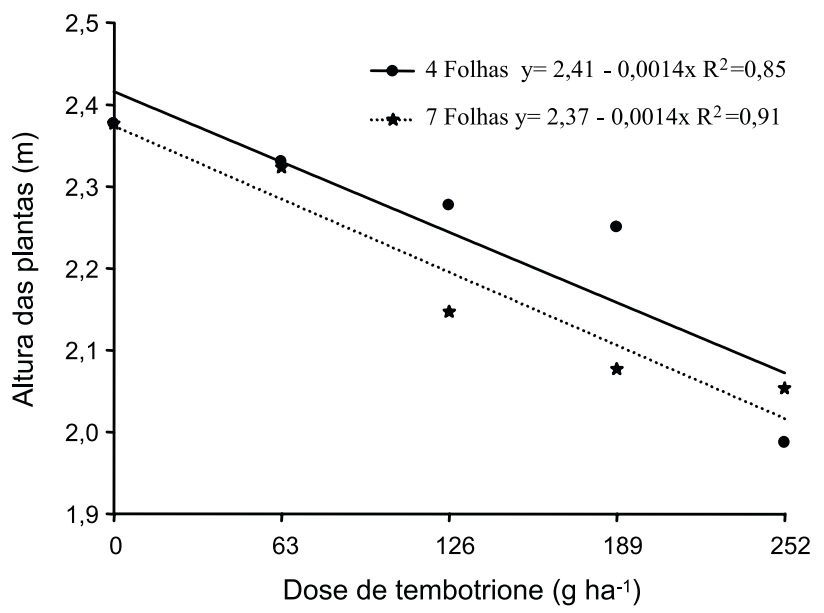

Figura 3 - Altura média das plantas de milheto, em função da dose do herbicida tembotrione e do estádio das plantas no momento da aplicação. do tembotrione (Figura 4 e Tabela 2). A interferência do herbicida em algumas variáveis avaliadas possivelmente refletiu em prejuízos à produção de grãos. Dentro do intervalo de doses estudado, a maior dose $\left(252 \mathrm{~g} \mathrm{ha}^{-1}\right)$ afetou a produção de grãos em 39 e $25 \%$ para as aplicações realizadas com quatro e sete folhas expandidas, respectivamente. Esses resultados evidenciam que as aplicações precoces intensificam a redução da produtividade de grãos do cultivar de milheto ADR-7010.

A interferência causada por plantas daninhas em milheto pode ocasionar perdas de até $36 \%$ sobre o rendimento da cultura (Carson, 1987), o que justificaria a necessidade do controle de infestantes nesta cultura. Dentre as opções de manejo, a possivel utilização do herbicida tembotrione não deve ser descartada. Caso seja levado em consideração o intervalo de doses recomendado para a cultura do milho (entre 75 e $100 \mathrm{~g} \mathrm{ha}^{-1}$ de tembotrione), as equações ajustadas aos dados de produtividade (Figura 4) indicam que o herbicida poderá causar injúria ao cultivar ADR-7010 e reduzir sua produtividade entre 7,3 e $11,4 \%$, caso a aplicação seja realizada no estádio de quatro folhas, e entre 4,9 a $7,4 \%$, para aplicação na fase de sete folhas. Sob condições normais de lavoura, essa redução de produtividade provavelmente seja menor do que as perdas qualitativas e quantitativas provocadas pela competição com plantas daninhas.

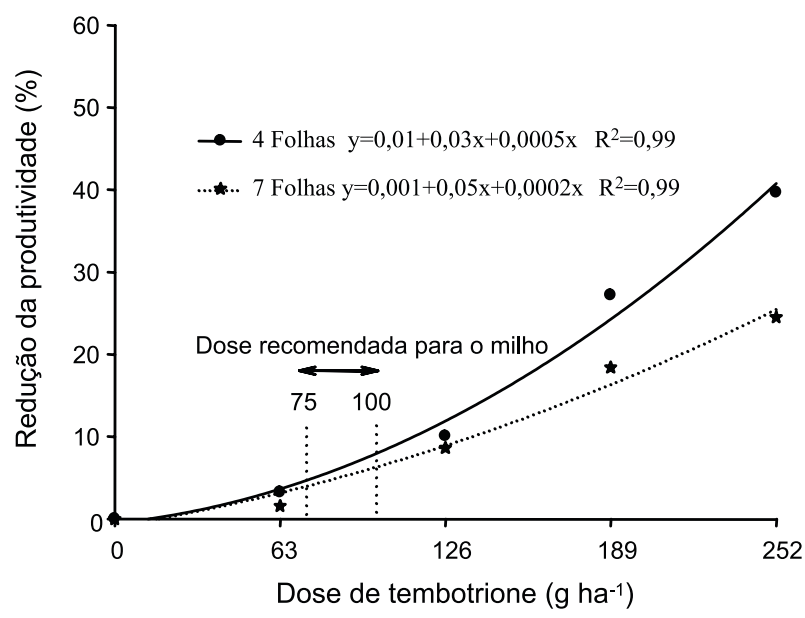

Figura 4 - Porcentagem média de redução do rendimento de grãos da cultura do milheto, em função da dose do herbicida tembotrione e do estádio das plantas no momento da aplicação. 
A grande rusticidade da cultura, relatada por vários autores (Scaléa, 1998; Randy \& Anderson, 2000; Trezzi \& Vidal, 2004), possivelmente aliada a possiveis mecanismos de detoxificação, pode explicar a recuperação ao estresse causado pelo herbicida. Novos trabalhos devem investigar a possibilidade de redução da intoxicação por meio da utilização de safeners. Outro aspecto a ser observado é o baixo risco de contaminação apresentado por esse herbicida. Avaliando o quociente de impacto ambiental (QIA) de diversos herbicidas, Karam et al. (2009) observaram que o tembotrione apresenta baixo risco de contaminação ambiental. Entretanto, é imprescindível a realização de novos estudos a fim de elucidar o período de carência desse herbicida, principalmente para o milheto utilizado na alimentação animal.

Conclui-se que o uso de tembotrione na cultura do milheto em áreas destinadas à produção de grãos mostra-se uma alternativa viável no controle de plantas daninhas e que a seletividade para a cultura é dependente da dose utilizada e do estádio fenológico da cultura no momento da aplicação.

\section{LITERATURA CITADA}

ABIT, J. M. et al. Differential response of grain sorghum hybrids to foliar-applied mesotrione. Weed Technol., v. 23, n. 1, p. $28-33,2009$.

BERGLUND, D. R. Proso millet in North Dakota. Fargo North Dakota State University, 1998. 7 p.

BOLLMAN, J. D. et al. Efficacy and tolerance to HPPDinhibiting herbicides in sweet corn. Weed Technol., v. 22, n. 4, p. 666-674, 2008.

CARSON, A. G. Improvement weed management in the draft animal-based production of early pearl millet in Gambia.

Trop. Pest Manag., v. 33, n. 2, p. 359-363, 1987.

DAN, H. A. et al. Seletividade de herbicidas aplicados na pós-emergência da cultura do milheto (Pennisetum glaucum). R. Bras. Milho e Sorgo, v. 8, n. 3, p. 297-306, 2009.

FARINELLI, R.; PENARIOL, F. G.; LEMOS, L. B. Eficiência do herbicida 2,4-D no controle de Raphanus raphanistrum $\mathrm{L}$. em pós-emergência na cultura do milheto. R. Bras. Milho e Sorgo, v. 4, n. 1, p. 104-111, 2005.

FELIX, J.; DOOHAN, D. J. Response of five vegetables crops to isoxaflutole soil residues. Weed Technol., v. 19, n. 1, p. 391-396, 2005.
GROSSMANN, K.; EHRHARDT, T. On the mechanism of action and selectivity of the corn herbicide topramezone: a new inhibitor of 4- hydroxyphenylpyruvate dioxygenase.

Pest Manag., v. 63, n. 3, p. 429-439, 2007.

KARAM, D. et al. Seletividade da cultura do milho ao herbicida clomazone por meio do uso de dietholate. R. Bras. Milho e Sorgo, v. 2, n. 1, p. 72-79, 2003.

KARAM, D.; SILVA, J. A. A.; FOLONI, L. L. Potencial de contaminação ambiental de herbicidas utilizados na cultura do milho. R. Bras. Milho e Sorgo, v. 8, n. 3, p. 247-262, 2009.

KISSMANN, K. G. Plantas infestantes e nocivas. São Paulo: BASF, 2007. Tomo I. 901 p.

LYON, D. J.; KNISS, A.; MILLER, S. D. Carfentrazone improves broadleaf weed control in proso and foxtail millets. Weed Technol., v. 21, n. 1, p. 84-87, 2007.

MITCHELL, G. D. W. et al. Mesotrione: A new selective herbicide for use in maize. Pest Manag., v. 57, n. 1, p. 120-128, 2001.

NDAHI, W. B. et al. Growth of pearl millet (Pennisetum americanum (L.) Leeke) as influenced by selected herbicide applications and delay in planting. In: VANDERLIP, R. L. (Ed.) Improvement of pearl millet. Second annual report. Manhattan: Kansas State University, 1980. p. $67-71$.

PACHECO, L. P. et al. Tolerância do milheto (Pennisetum americanum) ao 2,4-D. Planta Daninha, v. 25, n. 1, p. 173-179, 2007.

PATAKY, J. K. et al. Genetic basis for varied levels of injury to sweet corn hybrids from three cytochrome P450metabolized herbicides. J. Am. Soc. Hortic. Sci., v. 133, n. 1, p. 438-447, 2008.

PEREIRA FILHO, I. A. et al. Manejo da cultura do milheto. Sete Lagoas: Embrapa Milho e Sorgo, 2003. 17 p. (Circular Técnica, 29).

RANDY, L.; ANDERSON, A. Cultural system approach can eliminate herbicide need in semiarid proso millet (Panicum miliaceum). Weed Technol., v. 14, n. 1, p. 44-55, 2000.

SCALÉA, M. J. Perguntas \& respostas sobre o plantio direto. Infor. Agron., n. 83, p. 1-8, 1998. (Encarte técnico)

TREZZI, M. M.; VIDAL, R. A. Potencial de utilização de cobertura vegetal de sorgo e milheto na supressão de plantas daninhas em condições de campo: II- efeito da cobertura morta. Planta Daninha, v. 22, n. 1, p. 1-10, 2004.

Planta Daninha, Viçosa-MG, v. 28, n. 4, p. 793-799, 2010 